\title{
As ilhas de racionalidade e o saber significativo: o ensino de ciências através de projetos
}

Cátia Maria Nehring, ${ }^{1}$ Cibele Celestino Silva, ${ }^{2}$ José Análio de Oliveira Trindade, ${ }^{3}$ Maurício Pietrocola, ${ }^{4}$ Raquel Crosara Maia Leite, Terezinha de Fátima Pinheiro ${ }^{5}$

Curso de Doutorado em Ensino de Ciências Naturais/UFSC

O objetivo deste artigo é refletir sobre o ensino atual de ciências, sua relação com o cotidiano e o universo de interesse dos estudantes. A falta de relação deste ensino com a realidade vivenciada pelos alunos faz com que tenham um menor engajamento neste processo de aprendizagem, para o qual não vêem muito significado. Uma das razões deste problema está na seleção dos conteúdos disciplinares e na forma como são trabalhados nas aulas de ciências e a questão que se coloca é: como devemos proceder para que os alunos possam compreender o conhecimento científico como resposta a uma questão ou a um problema? Uma das possibilidades para o alcance deste objetivo é o desenvolvimento de atividades de modelização que, além de manter contato com os modelos científicos, permite a sua aplicação à realidade de forma significativa. Para intensificar essa aproximação entre o ensino de ciências

e o cotidiano, Gerard Fourez (1994) propõe a construção de ilhas interdisciplinares de racionalidade, na perspectiva de uma alfabetização científica e técnica. Para ele este é um meio de promover um ensino capaz de propiciar a autonomia, o domínio e a comunicação das tecnologias intelectuais elaboradas pela humanidade.

Neste sentido, ao mesmo tempo que apresentamos as etapas de construção de uma ilha interdisciplinar de racionalidade, propomos um exemplo da mesma em torno do tema: "um banho saudável".

\section{INTRODUÇÃO}

Muitas vezes é difícil fazer com que os alunos tomem, como seu, um problema formulado na escola. Os professores acreditam que se trata de verdadeiro problema científico, embora simplificado e adaptado pelos livros didáticos ao público estudantil. Desse modo, não conseguem entender os motivos que levam os alunos a se desinteressarem dos conteúdos científicos. Um exemplo deste tipo de problema seria o seguinte: como estariam distribuídos os elétrons do átomo de carbono em seus níveis de energia? E aqueles do átomo de sódio? Ou aqueles do átomo de molibdênio? Será que estas questões constituíram-se em problema para os cientistas, ou o são para os nossos alunos? Para os cientistas, provavelmente, os problemas que os instigaram foram: como era a estrutura de um átomo, onde estariam as cargas elétricas, onde se localizavam e como se comportavam. Certamente o desafio era construir um modelo

\footnotetext{
${ }^{1}$ Departamento de Matemática/UNIJUI

${ }^{2}$ Departamento de Física/UDESC

${ }^{3}$ Colégio de Aplicação/UFSC

${ }^{4}$ Departamento de Física/UFSC, com apoio parcial do CNPq

${ }^{5}$ Colégio de Aplicação/UFSC
} 
que respondesse a estas questões e após a determinação de um que descrevesse a estrutura dos níveis eletrônicos, realizar a sua distribuição para cada um dos átomos já não se constituiria mais em um problema. Seria uma decorrência da própria concepção atômica. Saber como proceder na distribuição dos elétrons passaria a ser um conhecimento importante para os cientistas. Polya afirma que "resolver um problema consiste em encontrar um caminho ali, onde previamente não se conhecia tal, encontrar uma saída para uma situação difícil, para vencer um obstáculo, para alcançar um objetivo desejado que não pode ser imediatamente alcançado por meios adequados" (citado por Carvalho e Gil-Perez, 1993). Nesse sentido, a distribuição atômica seria mais a aplicação de uma regra do que um verdadeiro problema. Por parte dos professores, existiria a certeza antecipada da existência de uma solução, visto tratar-se de um conteúdo cientificamente "velho". ${ }^{6}$ Por parte dos alunos, o jogo estabelecido na sala de aula faz com que admitam a existência de uma solução acessível ao seu nível, já que se trata de um conteúdo escolar. ${ }^{7}$

No exemplo citado, conceitos científicos como carga, elétrons e átomos são utilizados de tal modo que induzem à falsa idéia de se estar diante de um verdadeiro problema científico. Todavia, saber quantos elétrons "cabem" em camadas eletrônicas de um átomo não desperta muito interesse nos alunos. Questões como esta não lhes são familiares, nem apresentam relação com seu universo de interesse. Não inseridos no contexto científico, nem conscientes da relação existente entre a distribuição eletrônica e a estrutura da matéria, compreendem essa atividade como simples exercícios escolares. Essa impressão fica reforçada quando os alunos não conseguem perceber a vinculação que tal conhecimento tem com o mundo a sua volta. $A$ falta de relação com seu cotidiano faz com que não vejam significado em tais conhecimentos, por isso não incorporam tais proposições como seus problemas e nem se motivam para buscar soluções para eles.

No entanto, várias vezes, professores e livros didáticos apresentam aos alunos atividades desse tipo como se fossem verdadeiros problemas. Este é um caso de problemas escolares que não se constituem em verdadeiros problemas, nem para os alunos e nem para os cientistas.

Uma das razões deste impasse está na seleção dos conteúdos disciplinares. Há uma tradição estabelecida que identifica o conhecimento científico escolar como uma simplificação da ciência de referência. Acredita-se que na simplificação não há perda na essência do conhecimento, mas apenas uma limitação de profundidade, centrada majoritariamente na definição dos conceitos envolvidos. O conhecimento científico escolar guardaria seu valor por não ter sido modificado estruturalmente, ou seja, sua legitimidade enquanto conteúdo curricular estaria preservada por continuar a ser um conhecimento legitimado cientificamente. Esta característica por si só seria suficiente para que os alunos se envolvessem com sua aprendizagem e posterior utilização.

Entretanto existem questões relacionadas ao mundo científico que conseguem despertar interesse nos alunos. Na sua relação cotidiana com o mundo, estabelece-se uma

\footnotetext{
${ }^{6}$ Kunh (1995) se refere a esse tipo de atividade como exemplares, fundamentais na formação dos futuros cientistas. Para saber mais, veja Zylbersztajn, 1998.

${ }^{7}$ Veja em Dupin e Johsua, 1993, no cap. 5, a noção de "Contrato Didático".
} 
dimensão problemática para a qual eles buscam soluções. As diversas pesquisas em concepções alternativas (Zylbersztajn, 1985, Villani, Pacca e Housoume, 1985, Peduzzi e Peduzzi, 1985) têm indicado o grau de sofisticação que atinge as construções conceituais elaboradas pelos alunos, a partir de situações do cotidiano. O mais surpreendente nesses resultados de pesquisa é a quase inexistência de conhecimento científico nas soluções apresentadas. Os alunos parecem não perceber a existência de uma relação entre aquilo que aprendem nas aulas de ciências e os problemas formulados fora dela. O conteúdo escolar Ihes parece adaptado na resolução de exercícios-padrão e na realização de provas, para satisfazer as expectativas dos professores na sala de aula. A dicotomia gerada entre o conhecimento escolar e o conhecimento do cotidiano desqualifica o primeiro, conferindo-lhe apenas um status de "verniz" cultural.

Todavia, o conhecimento científico, mesmo aquele transportado para a escola, mantém seus vínculos com a realidade e por conseqüência com o cotidiano de todos. Por que então isso não fica explícito na ciência escolar?

\section{A TRANSPOSIÇÃO DIDÁTICA E OS MODELOS}

É difícil acreditar que a transposição de conhecimento entre universos tão distintos como aquele da pesquisa e da sala de aula não esteja sujeita a modificações significativas, como parecem crer educadores e professores de ciências. Os conteúdos de ciências na escola não são apenas simplificações dos conteúdos das ciências de referência. Ao ser transposto para o contexto escolar, determinados elementos deste conhecimento desaparecem e outros são criados. Este processo de transformação resulta num conhecimento descaracterizado e descontextualizado. Embora seja uma transformação necessária, na maioria das vezes, resulta na desconsideração de aspectos que seriam fundamentais para que os alunos pudessem compreender o conhecimento científico como o resultado de um processo que tem por objetivo a busca de respostas a problemas.

$\mathrm{Na}$ educação científica as relações de ensino/aprendizagem se estabelecem sobre um conhecimento específico que é fundamentado na ciência oficial. Entretanto, há uma interpretação ingênua de que os conteúdos escolares de ciências são simplificações do conhecimento produzido pelos cientistas. Chevalard (1985) mostrou que "os objetos designados a ensinar não poderiam ser analisados como uma simplificação de objetos mais complexos, originados na comunidade dos cientistas. Eles são o resultado de uma construção qualitativamente diferente" (Dupin e Johsua, 1993: 194). Um objeto a ensinar é conseqüência de uma história particular, sendo o resultado de um tratamento didático que obedece a restrições específicas.

As transformações sofridas por determinado elemento do conhecimento, ao sair do ambiente científico até se tornar elemento ou objeto de ensino, são denominadas de transposição didática. Estas transformações são determinadas por várias esferas intermediárias, constituídas por grupos que exercem pressão, moldando o objeto de conhecimento escolar. Estes grupos constituem a noosfera. Dentre outros, integram a noosfera os pesquisadores ou cientistas, os autores de livros didáticos, o poder político, o currículo, os especialistas e os professores. 
A transposição didática permite a distinção de três estatutos ou patamares de saber: o saber sábio, o saber a ensinar e o saber ensinado. O saber sábio é constituído pelo produto da atividade científica. Os cientistas pertencem ao grupo que produz e determina o saber sábio. Para que um conteúdo do saber sábio se torne um conteúdo do saber a ensinar, ou seja, um conteúdo de ensino, ele passa por alterações nada simples, que são determinadas inicialmente por uma lógica conceitual originada no interior do saber sábio.

O fato de um saber a ensinar estar presente ou definido nos manuais e livros didáticos, nas propostas curriculares ou nos planos de ensino não é garantia de que ele chegue, necessariamente, até o aluno. Há, portanto, um universo mais particular, o saber ensinado. Embora tenhamos nos referenciado como um caso particular do saber a ensinar, o saber ensinado é também repleto de características específicas. Para o saber ensinado concorrem mais acentuadamente os grupos da noosfera vinculados à comunidade escolar, como os diretores, os proprietários de estabelecimentos de ensino, os supervisores e orientadores educacionais, a comunidade dos pais e os professores. São inúmeros os aspectos que concorrem para a definição do saber a ser ensinado, mas pode-se identificar que ele é definido pela possibilidade de um controle social e legal da aprendizagem. Assim, o conteúdo nele presente deve atender aos seguintes requisitos:

$1^{\circ}$ - ser potencialmente ensinável, ou seja, pelo menos teoricamente, poder ser aprendido pelo aluno a que se destina. Para o atendimento deste requisito são levadas em consideração a faixa etária dos alunos, a especificidade do curso e da disciplina escolar dos quais fará parte.

$2^{\circ}$ - possibilitar a elaboração de objetivos de ensino, de exercícios, avaliações ou trabalhos práticos (Pinheiro, 1996).

Embora, na maioria das vezes, esses requisitos tenham sido levados em consideração na definição do saber a ensinar, especialmente pelos livros didáticos, a influência dos professores nessa esfera do saber é determinante. Isto porque a ênfase em determinadas unidades do conteúdo, a maneira como ele é abordado, os exercícios e a avaliação passam necessariamente pela decisão do professor e esta depende, dentre outras coisas, da sua formação e de seu entendimento a respeito das ciências de referência, dos conteúdos de ensino e dos alunos.

Uma questão importante presente no processo de transposição didática diz respeito à "organicidade" do conhecimento científico. O sistema didático não consegue dar conta de toda a sua complexidade, por isso este conhecimento é apresentado em fragmentos, sucessão de capítulos e lições, muitas vezes desconsiderando o fato de que um conceito científico ganha significado e valor no interior de uma estrutura teórica (Robilotta, 1985).

Esta forma de apresentação do conhecimento científico não resulta numa nova estrutura organizacional e o aluno a percebe como uma série de afirmações desconectadas, completamente distanciadas do mundo em que ele vive. Isto porque o conteúdo científico escolar se apresenta como se tivesse existência independente, ou seja, como se o conhecimento científico que o originou não tivesse sido elaborado a partir de um esforço intelectual de interpretação do mundo real. 
Para Bunge (1974: 13) a conquista conceitual da realidade começa com as idealizações. Esta conquista ocorre quando, pela classificação de traços comuns, estabelece-se o "objeto-modelo" ou "modelo conceitual" de uma coisa ou de um fato e se atribui a ele propriedades possíveis de serem tratadas por teorias. A construção de uma teoria do objetomodelo implica na construção de um modelo teórico.

Bunge define modelo teórico como "um sistema hipotético-dedutivo que concerne a um objeto-modelo, que é, por sua vez, uma representação conceitual esquemática de uma coisa ou de uma situação real ou suposta como tal" (Bunge, 1974: 16). Ele enfatiza também que todo modelo teórico é parcial e aproximativo, uma vez que a observação, a intuição e a razão, que são componentes do trabalho científico, não podem, por si só, permitir o conhecimento do real. Entretanto, assinala que o método da modelagem e da sua comprovação mostrou-se bem sucedido na apreensão da realidade.

Drouin (1988) chama a atenção dos vários empregos para modelos e afirma que, em algumas situações, ele é utilizado significando leis ou teorias já construídas, com um sentido retrospectivo, enquanto que em outras ocasiões ele é caracterizado como construção mental, que visa a previsão e/ou medida de fenômenos. Para esta autora, em qualquer situação fica evidente que o modelo desempenha um papel característico em relação ao conhecimento: ele é um objeto de substituição que pode ser manipulado. Ele é uma construção da mente, que permite substituir um conjunto de variáveis, que, por diversas razões, não são diretamente acessíveis à experiência. Este modelo é construído em função de alguma idéia que se faz do real; idéia que pode estar ligada às observações, aos conhecimentos anteriores e/ou à formulação do problema. No caso do modelo planetário do átomo, os elementos a manipular estão ligados entre si por estruturas abstratas, enquanto que no modelo quantificado de fluxo de matéria e energia em um ecossistema é a matematização que vincula esses elementos.

Para Dupin e Johsua (1993), na esfera do saber a ensinar, o modelo não é um dado de partida, mas é um objetivo declarado de ensino. Como conseqüência, ocorre a dissociação do modelo em conceitos apresentados inicialmente como independentes, para posteriormente serem relacionados entre si. $O$ modelo é então dessintetizado, criando um quadro epistemológico artificial, específico do projeto didático. O saber a ensinar define conteúdos e, muitas vezes, a ordenação dos mesmos, enquanto que o saber a ser ensinado é o conhecimento linearizado, cumulativo, às vezes recorrente, no qual há um "tempo didático", que é diferente do "tempo lógico" do saber de referência. O tempo didático resulta em seqüências didáticas, com uma lógica própria, que não tem compromisso com a lógica do conhecimento de referência. $O$ ponto de contato entre o saber sábio e o saber a ser ensinado constitui-se na tentativa de manter um diálogo com a realidade. Nesta tentativa, o saber ensinado preserva algumas características e guarda algumas semelhanças quanto aos conceitos, experimentos e alguns dos problemas originais presentes na ciência.

Para estes autores, no saber ensinado, um modelo deve responder a muitas necessidades: ele deve ter coerência interna, deve manter ligações com o real, deve fornecer um quadro interpretativo e deve ser susceptível de decomposição, permitindo apresentar um processo de reconstrução.

Para Larcher (1996), aprender ciências é adquirir conhecimentos que são considerados válidos, úteis, frutíferos, mas é também admitir o caráter aproximativo, parcial e 
provisório do conhecimento de um mundo que não podemos apreender em toda sua complexidade. Isto pode ser conseguido através de um processo de construção de modelos que, além de manter contato com os modelos científicos, permita a compreensão de problemas da realidade vivenciada pelos alunos, de maneira que os modelos sejam percebidos como possíveis de serem aplicados à realidade de forma significativa.

\section{A EDUCAÇÃO NA PERSPECTIVA DA ALFABETIZAÇÃO CIENTÍFICA E TÉCNICA}

Para Pietrocola (1999), a intensificação nas estratégias de construção do conhecimento são importantes para os alunos na medida em que eles possam perceber que 0 conhecimento científico aprendido na escola serve como forma de interpretação do mundo que os cerca. E para isso considera que a realidade deva ser objeto da educação científica, enfatizando o conhecimento construído pela ciência como esboço dessa realidade e fazendo disso um dos principais objetivos da educação científica.

Na mesma direção, Fourez $(1994)^{8}$ propõe a Alfabetização Científica e Técnica como estratégia pedagógica e epistemológica para tratar o ensino de ciências. O autor considera que a Alfabetização Científica e Técnica é definida por um contexto no qual os saberes científicos procuram gerar alguma autonomia, possibilitando que o aprendiz tenha capacidade para negociar suas decisões, alguma capacidade de comunicação (encontrar maneira de dizer) e algum domínio e responsabilização face a situações concretas.

Desta forma, uma maneira de enfrentarmos as questões levantadas no início do artigo, seria a elaboração de modelos interdisciplinares para representar as situações cotidianas. A construção de tais modelos é necessária para a compreensão destas situações e para que o indivíduo possa agir diante delas.

Fourez chama a cada um destes modelos de ilha interdisciplinar de racionalidade, definindo-a como sendo uma invenção de uma modelização adequada para uma situação específica. Para esta construção são utilizados os conhecimentos de diversas disciplinas e também os saberes da vida cotidiana.

Uma ilha de racionalidade designa uma representação teórica apropriada de um contexto e de um projeto, permitindo comunicar e agir sobre o assunto. Refere-se a um contexto e a um projeto particular, para o qual julga-se interessante construir uma representação.

Ao se construir uma ilha de racionalidade surgirão questões específicas ligadas a determinado conhecimento científico que poderão ser respondidas ou não conforme o caso. Estas questões abertas são denominadas de caixas-pretas. O contexto e os objetos do projeto orientam a abertura ou não das caixas-pretas. Uma caixa-preta aberta significa a obtenção de modelos que possam relacionar os fatos conhecidos, gerando explicações. Nesse contexto, uma ilha de racionalidade ancora-se na construção de modelos, visando a solução de problemas de interesse a partir do cotidiano dos indivíduos. Segundo Fourez, a teorização proposta na ilha de racionalidade é quase sempre interdisciplinar, pois é muito difícil propor

\footnotetext{
${ }^{8}$ Existe uma tradução argentina desta obra, intitulada Alfabetización Científica y Tecnológica. Colection Nuevos Caminos, Ediciones Colihue, 1997.
} 
uma solução a um problema concreto, engessado pelas limitações e abstrações de uma disciplina particular.

Como prática, a construção de uma ilha de racionalidade implica em cruzar saberes provenientes de muitas disciplinas e conhecimentos da vida cotidiana, para estruturar um modelo (ou uma representação, ou uma teorização). A eficiência e o valor de uma ilha de racionalidade estão vinculados a sua capacidade de dar uma representação que contribua para solucionar um problema preciso.

Ao adotar os problemas extraídos do cotidiano como fio condutor ao trabalho de teorização, fica determinada uma transposição que não tem o saber sábio (disciplinar) como referência única. Nesse sentido, a Alfabetização Científica e Técnica imporia uma nova sistemática na transposição didática, sendo os diversos saberes, introduzidos em sala de aula, fruto de seleção e ponderação e determinados pelo contexto do problema a ser resolvido. $O$ conhecimento disciplinar, contido na dimensão do saber sábio, perderia definitivamente sua aura de verdade geral, em favor de um saber legitimado pelo seu potencial explicativo local e pela capacidade de gerar soluções práticas. A dessintetização presente no processo de transposição didática seria contrabalançada pela estruturação elaborada em torno do problema a resolver. Dá-se dessa forma um corpo organizacional próprio ao conhecimento científico escolar, evitando com isso a fragmentação. Nesta perspectiva, a capacidade de construir ilhas de racionalidade parece ao autor essencial à inserção mais ou menos autônoma de cidadãos na sociedade, dando significado ao que será aprendido.

Nesse sentido, Fourez acrescenta que

importa então sempre deixar em evidência os critérios e os projetos subjacentes aos processos científicos. Em vez de simplesmente ensinar aos alunos a observar-medircomparar-seriar-classificar, como se tais processos fossem determinados por eles mesmos, é melhor dizer que se observa utilizando técnicas particulares de observação, que se mede em função de critérios que pareçam interessantes, que se compara segundo características selecionadas, que se realiza seriação em relação aos objetivos e que se classifica segundo uma representação teórica previamente aceita (Fourez, 1994: 65).

\section{Os saberes de referência, sejam eles científicos ou tecnológicos, seriam importantes na medida em que subsidiam os debates surgidos no cotidiano dos indivíduos.}

A ocultação sistemática dos contextos problemáticos presentes na produção do conhecimento científico ocasiona a perda de significado, tornando os alunos dependentes dos professores. Eles passam então a procurar inferir a respeito das expectativas do professor, como forma de dar sentido às questões e/ou aos exercícios propostos em aula.

Um ensino descontextualizado de modelos científicos pode provocar nos alunos a impressão de que a ciência não interessa, não serve para nada e que ela trata de coisas que só interessam aos cientistas.

Se já está claramente definido por pesquisas em ensino de ciências que as concepções prévias dos alunos interferem na aprendizagem de conceitos científicos, parece 
menos claro que o mesmo possa acontecer com as concepções prévias de professores. "As nossas representações de ciência e de tecnologia também não serão obstáculos às renovações pedagógicas necessárias?"(Fourez, 1994: 66). Aceitar que exista interesse e motivação na aprendizagem de conhecimento científico, independentemente dos contornos definidos pelas situações reais, pela história, pelos projetos pessoais e coletivos, configura-se como uma concepção prévia de educação científica cristalizada por anos de formação e atuação profissional. Por outro lado, qual será a imagem que fazemos da tecnologia? Será ela concebida apenas como um "fazer prático", e desta forma, inferior ao fazer científico? Não seriam estas concepções verdadeiros obstáculos epistemológicos a uma educação científica vinculada às necessidades cotidianas dos alunos?

Como motivo para promover a Alfabetização Científica e Técnica, Fourez apresenta razões humanistas quando se refere à autonomia do indivíduo e suas possibilidades de agir e comunicar e razões econômicas quando se trata de formar engenheiros como mão-de-obra qualificada. Isto porque julga que a educação científica deve passar por um ensino contextualizado e não por um ensino que se justifica por si sem relações com o mundo real.

Nesta perspectiva, "ser alfabetizado científica e tecnicamente significará sobretudo que se tomará consciência de que as teorias e modelos científicos não serão bem compreendidos se não se sabe por que, em vista de que e para que foram inventados" (Fourez 1994: 67).

\section{ILHA DE RACIONALIDADE E SUAS ETAPAS DE CONSTRUÇÃO EM TORNO DE UM "BANHO SAUDÁVEL"}

O que determina os critérios sobre o corpo de conhecimento a ser trabalhado é o projeto, ou seja, para o que e para quem ele se destina. "Ele visa produzir uma representação teórica apropriada em uma situação precisa e em função de um projeto determinado" (Fourez et al. 1993: 121). Assim, um projeto, que trata sobre a melhor forma de manter uma sala iluminada com luz natural, dependerá dentre outros fatores da utilização que terá a sala e em que região ela se localiza.

O projeto pode ser utilitário - como no caso de um projeto de construção de uma ponte - ou cultural - como no caso de se conhecer sobre o uso do fogo pela humanidade ao longo de sua História, ou sobre o conceito de pressão em vários grupos humanos.

Os conhecimentos de diversas disciplinas serão utilizados para construir uma representação da situação, em que a ilha interdisciplinar de racionalidade constitui-se na própria representação, sendo o modelo teórico o meio de comunicar o que vai ser feito sobre a situação. Assim, a definição sobre o que será feito na atividade não é determinada pelas diversas disciplinas vinculadas ao tema, mas pelo projeto, por sua finalidade e por seu contexto. Neste sentido, o próprio conhecimento disciplinar a ser trabalhado dependerá dos limites definidos pelo projeto em questão, negociado pelos diversos atores que dele tomarão parte.

Um dilema geralmente presente na prática interdisciplinar reside no fato dos professores se sentirem obrigados a escolher entre o pragmático e o teórico, pois o trabalho interdisciplinar é uma atividade essencialmente direcionada. Então a finalidade da prática interdisciplinar pode ser utilitária, mas também pode ser teórica, na medida em que, no último 
caso, ela vise dar uma representação conceitual e fornecer uma linguagem da situação (Fourez et al. 1993: 123).

Quem decide o rumo do trabalho é a equipe - que pode ser constituída por profissionais de uma empresa pública ou privada, um grupo de professores de uma escola, grupo de alunos e professor - ou um indivíduo. Não há necessidade de uma equipe pluridisciplinar para realizar um trabalho interdisciplinar. Basta que se esteja aberto a fazer as consultas aos especialistas, se necessário. Seja em equipe, seja individualmente, o que fornece um quadro e uma estrutura ao trabalho interdisciplinar é o projeto e as decisões tomadas a partir dele: isto é o que permite delimitar a pesquisa.

Para construir a ilha de racionalidade são propostas algumas etapas, de modo a permitir que o trabalho vá sendo delimitado para que atinja sua finalidade. Embora apresentadas de maneira linear, elas são flexíveis e abertas, em alguns casos podendo ser suprimidas e/ou revisitadas, quantas vezes a equipe julgar necessário. A equipe é também quem determina o tempo de cada uma delas, de acordo com os objetivos, disponibilidades e necessidades. Elas servem como um esquema de trabalho, de modo a evitar que ele se torne tão abrangente que não se consiga chegar ao final.

Para que o projeto e o contexto sejam claramente definidos é recomendável que a situação seja expressa por meio de uma questão ou pela descrição da situação, da maneira mais precisa possível. Baseados nessa idéia de abordagem por projetos, e visando torná-la uma proposta concreta, apresentaremos a seguir um exemplo de construção de uma ilha de racionalidade sobre a seguinte questão: "Como tomar um banho saudável para o corpo e para o bolso?"

Esta proposta pretende ser um exemplo a ser aplicado na disciplina de ciências de $8^{\text {a }}$ série do ensino fundamental. Em vista disso alguns assuntos deverão ser abordados de maneira superficial, isto é, nem todas as "caixas-pretas" serão abertas em profundidade. Vale lembrar que o contexto no qual a escola está inserida determinará as escolhas realizadas ao longo do processo de construção da ilha de racionalidade. Assim, o que apresentamos não deve ser encarado como um exemplo a ser fielmente seguido, mas como uma tentativa de apresentar possibilidades de procedimentos utilizáveis para o professor em sala de aula.

\section{Etapa 1 - Fazer um clichê da situação}

Esta etapa tem por objetivo fazer os alunos expressarem como eles entendem espontaneamente o que é um banho saudável sem construir uma representação crítica e rigorosa. É uma descrição espontânea semelhante à problematização inicial proposta por Freire (1970). É o ponto de partida da pesquisa. Por meio dele a equipe levantará todos os tipos de questões possíveis, abertas e específicas. É como se fosse a primeira foto da situação. Ela parte da experiência cotidiana e, às vezes, revela pré-julgamentos profundos. Nela serão refletidas as idéias intuitivas do grupo, sem preocupação com nenhum tipo de formação especial. Pode-se também optar pela exposição de um técnico, ou ainda, pela desmontagem de um equipamento a estudar (Fourez et al. 1993: 125).

Nesta etapa é bom distinguir as idéias compartilhadas (definidas como "os fatos") e aquelas que são objeto de debates ("hipóteses ou suposições") ou julgamento de valor. 
Exemplos de perguntas que podem ser feitas a respeito de um banho: por que nos banhamos? quais práticas podem ser substituídas e por quê? como funciona? quem utiliza? quais são, à primeira vista, suas vantagens e inconveniências? o banho tem o mesmo significado nas várias culturas? qual a origem do banho? quais os fatores econômicos ligados a um banho? quais os setores da sociedade que podem ser associados a um banho? por que relacionamos a ele higiene e saúde? por que não há entrada de água na nossa pele quando nos banhamos? pode-se tomar banho após uma refeição? um simples banho pode causar problemas ambientais?

\section{Etapa 2 - Elaborar o panorama espontâneo}

É uma etapa na qual busca-se ampliar o clichê através da formulação, pelo professor e pelos alunos, de outras questões relevantes relacionadas com o projeto a ser desenvolvido e que ou não foram levantadas no primeiro clichê ou foram abandonadas. Esta etapa ainda é bastante espontânea, trata-se de questionar e lançar dúvidas ao invés de responder e fornecer explicações. Nesta etapa, caracterizada pela compreensão e apreensão da posição dos alunos frente ao projeto, ainda não se faz apelo aos especialistas, porém a experiência do professor é fundamental na definição das questões cujo critério para a escolha é o seu vínculo com o projeto a ser desenvolvido. Esta etapa constitui-se das ações descritas a seguir:

- $\quad$ Listagem dos atores envolvidos

Procura-se listar todas as pessoas que podem ser relacionadas com o ato de tomar banho e que o projeto julga necessário selecionar. Podem ser grupos sociais ou indivíduos.

Exemplos: os alunos (todos os que gostam de tomar banho e aqueles que não gostam), os consumidores (que podem ser representados pelos pais de alunos, professores, diretores), os produtores de energia, os fornecedores de água, os fabricantes de chuveiros, os fabricantes de produtos de higiene, os que compram e vendem tais produtos, materiais relacionados a um banho, os técnicos e acionistas de usinas elétricas, publicitários ...

- Pesquisa de normas e condições impostas pela técnica

É o momento de levantar as normas e/ou leis que regem situação, do ponto de vista técnico, ético ou comercial, bem como as normas definidas pela cultura. Como exemplo podemos citar as regras sobre datas de validade, normas de qualidade e segurança de chuveiros a gás ou elétricos, preocupação com a preservação do meio ambiente, etc.

- A lista dos jogos de interesse e das tensões

São levantados questionamentos a respeito das vantagens, desvantagens, valores, escolhas relacionadas ao problema proposto pelo projeto.

Exemplos de tensão: entre os prazeres de um banho e o seu custo e suas conseqüências sobre a saúde; problemas na pele e cabelo e conseqüências não imediatas no meio ambiente; interesses dos consumidores versus interesses dos industriais. (Dificuldades para um adolescente de $8^{a}$ série em enxergar os resultados de suas ações em algo que parece tão distante no tempo e no espaço - imediatismo juvenil). 
No que se refere aos jogos de interesse, outro aspecto que pode ser levantado se refere ao próprio trabalho escolar, para o qual contribuem restrições quanto ao tempo disponível para o desenvolvimento de uma atividade, conhecimento do professor, material bibliográfico e experimental disponíveis, etc.

- Listagem das caixas-pretas possíveis para o problema proposto

É a determinação das caixas-pretas que se pode abrir. Elas são subsistemas materiais ou conceituais que se pode estudar. A escolha das caixas-pretas que deverão ser abertas dependerá do contexto e do projeto.

Exemplos de caixas-pretas sobre o assunto: potência elétrica, lei de Ohm, aquecimento por efeito Joule, tipos de aquecimento e de chuveiros, tempo necessário para o banho, o design do chuveiro, o modo como é construído, os acessórios, efeito da temperatura sobre o organismo humano, questões de segurança, os diversos produtos utilizados, hábitos de uso, imagem do banho na sociedade, os usos imprevistos, os riscos de incêndio e queimaduras, a determinação do preço do chuveiro, as estratégias publicitárias, a educação para a saúde, influência da higiene sobre a saúde, as recomendações dos médicos, a influência da cultura e da economia sobre o banho, a importância da imagem dada ao corpo na sociedade e sua relação com a higiene, a composição dos produtos de higiene, a evolução do banho no curso da História, a influência da publicidade sobre o comportamento das pessoas e seu impacto em nível psicológico, a oposição entre os diversos interesses, o impacto ambiental, células e tecidos, pressão da água, diâmetro dos tubos, altura da caixa-d’água, etc.

- Lista de bifurcações

Uma bifurcação "designa um momento em que o ator social tem que fazer opção entre dois caminhos, duas estratégias" (Fourez, 1994: 96). Corresponde a colocar o estudante diante de situações e levá-lo a optar frente aos argumentos já discutidos. Estas escolhas são técnicas, podendo estar relacionadas com as escolhas das caixas-pretas a serem abertas, mas podem depender de jogos de interesses, correspondendo a decisões éticas e políticas.

Exemplos de bifurcações: os diferentes tipos de chuveiro, as opções sobre a forma de aquecimento da água, a importância dada à segurança, à durabilidade, ao preço, algumas escolhas técnicas sobre o material do chuveiro, sobre a instalação de um fusível ou um fio terra. A escolha entre um banho longo e um banho econômico, a escolha em matéria de educação para a saúde e a informação da população, a escolha de programas de pesquisa neste assunto, etc.

- Lista dos especialistas e especialidades pertinentes

Tem por objetivo aprofundar as informações necessárias de que o grupo não dispõe e corrigir representações equivocadas dos membros da equipe. A cada caixa-preta pode corresponder um especialista ou uma especialidade que se poderia consultar mais tarde. Os usuários (consumidores) também podem ser considerados especialistas.

Exemplo de lista de especialistas: biólogos, psicólogos e psiquiatras, sociólogos, médicos, etnogeógrafos, religiosos, historiadores, químicos, bioquímicos, físicos, biotecnólogos, 
ecologistas, economistas, políticos, advogados, filósofos, consumidores, esteticistas, dermatologistas, matemáticos, publicitários.

\section{Etapa 3 - Consulta aos especialistas e às especialidades}

Quando entre os membros do grupo que desenvolve o projeto não há quem possa esclarecer ou discutir a respeito de determinado assunto envolvido na situação, pode haver a necessidade de consultar especialistas. A equipe do projeto é que define quais dos especialistas listados serão consultados. Esta consulta permitirá a definição de abertura das caixas-pretas. Dois tipos de critérios para a escolha dos especialistas são preponderantes: a situação e o projeto selecionado no início e os objetivos escolares.

\section{Etapa 4 - Indo à prática}

É uma etapa de aprofundamento, definido pelo projeto e pelos produtores da ilha de racionalidade, na qual ocorre o confronto entre a própria experiência e as situações concretas. Deixa-se de pensar sobre a tecnologia da situação para confrontá-la mais diretamente com a prática. Esta etapa pode ser efetuada de várias maneiras: interrogando-se um especialista, desmontando-se um equipamento, inteirando-se melhor a respeito de outros aspectos do equipamento, etc.

Exemplos: examinar um chuveiro, entrevistar pessoas sobre o tempo e o horário do banho, temperatura da água, hábito de tomar banho diário, indagar se o indivíduo canta durante o banho, se usa xampu, sabonetes, etc. Decodificar as mensagens publicitárias de um canal de TV, assim como as atitudes de defesa dos consumidores em relação a elas. Análise das contas de água e luz.

\section{Etapa 5 - Abertura aprofundada de algumas caixas-pretas e descoberta de princípios disciplinares que são base de uma tecnologia}

É neste momento da proposta que se pode trabalhar o rigor de uma disciplina específica, a base original de tratamento do assunto que se pretende examinar, e até mesmo estudar, rapidamente, tópicos clássicos do programa escolar. Esta etapa é caracterizada pelo estudo aprofundado, por uma pesquisa mais minuciosa de algum ponto abordado pelo projeto, presentes na abertura de caixas-pretas. Isto pode acontecer com o auxílio de especialistas ou não, entretanto não se buscará esgotar todo o conhecimento ligado às ciências da natureza. $A$ abertura das caixas deve estar, em última análise, condicionada ao contexto, ao projeto, aos produtores e destinatários da ilha de racionalidade.

Deve-se lembrar que o objetivo primordial desta proposta é a alfabetização técnicocientífica, que busca a autonomia dos indivíduos frente ao mundo científico-técnico em que vivem, e portanto, mesmo fazendo apelo às disciplinas específicas tradicionais, é preciso escolher estratégias que privilegiem esta orientação. Neste sentido, questões de natureza cultural também podem se constituir em caixas-pretas passíveis de abertura e que se constituirão em objeto de modelização, a exemplo do que ocorre em ciências naturais.

Exemplos: um biólogo para estudar os benefícios e malefícios do ato de banhar-se, em termos de células e tecidos da pele; um dermatologista para orientações sobre saúde; um esteticista para conselhos sobre beleza; um químico e farmacêutico sobre os produtos de 
higiene pessoal (propriedades químicas e produção); um sociólogo para discutir a diferença de hábitos do banho em diversas sociedades; um técnico para discutir as normas de qualidade dos chuveiros; um filósofo para discutir questões de significado sobre este assunto; engenheiros florestais para comentar sobre a degradação e preservação do meio ambiente.

\section{Etapa 6 - Esquematização global da tecnologia}

Esta etapa é uma síntese da ilha de racionalidade produzida. Esta síntese pode ser uma figura ou um resumo contendo os principais pontos da ilha de racionalidade e especificando as caixas-pretas que podem ser abertas pelo professor, dependendo da conveniência. Após estes processos, é possível dar uma representação teórica de um banho saudável: uma ou mais ilhas de racionalidade a esse respeito.

\section{Etapa 7 - Abrir algumas caixas-pretas sem a ajuda de especialistas}

Todos construímos intuitivamente explicações para situações do cotidiano, mesmo sem dispormos de todos os conceitos científicos e técnicos envolvidos. Entretanto, estas soluções são parciais e muitas vezes precisam ser completadas com conhecimentos científicos e/ou técnicos. Isto requer o auxílio de especialistas. Estas construções provisórias são de extrema importância pois produzem o sentimento de autonomia frente o cotidiano. Desta forma, a busca de modelos aproximados deveria ser um objetivo educacional perseguido na escola. Explicitando o caráter provisório e limitado de tais conhecimentos, não haveria o risco de gerar falsas expectativas para com soluções ainda provisórias, deixando-se aberta a possibilidade de aprofundamento, posteriores frente a necessidade da tomada de decisões concretas. Mesmo que estes modelos aproximados não tenham todo o rigor necessário, eles são importantes pois, tratam de situações da vida cotidiana: mais vale uma explicação pobre que nenhuma explicação (Fourez et al. 1993).

Geralmente os problemas e situações da vida cotidiana exigem uma tomada de decisão concreta que envolve a avaliação de vários fatores interdisciplinares e, portanto, a consulta a vários especialistas. Como quase nunca temos todos os peritos disponíveis, deve-se incentivar os alunos a construir ponderadamente ilhas de racionalidade para compreender tais situações de forma autônoma.

Exemplo: quais atitudes deve tomar uma pessoa que tem pele ressecada? após as refeições o banho provoca indigestão?

\section{Etapa 8 - Síntese da ilha de racionalidade produzida}

Para sintetizar a ilha de racionalidade é necessário cruzar elementos variados de maneira objetiva. Para tanto, Fourez coloca que quatro questões devem ser respondidas:

a) O que estudamos nos ajuda a "negociar" com o mundo tecnológico examinado?

b) Ele nos deu uma certa autonomia no mundo científico-técnico na sociedade em geral?

c) Em que os saberes obtidos nos ajudam a discutir com mais precisão quando da tomada de decisões? 
d) Em que isto nos dá uma representação de nosso mundo e de nossa história que nos permite melhor situar-nos e fornecer uma real possibilidade de comunicação com os outros? (Fourez, 1994).

O processo interdisciplinar proposto é um modelo pedagógico que fornece um quadro que permite o estudo de questões para as quais um processo disciplinar é muito pequeno. Ele propõe um método para aprender a pensar orientado por projetos, como fazem os engenheiros, os arquitetos, os médicos e, no fim das contas, como pensamos quando não queremos reduzir a uma só dimensão as situações concretas que encontramos no cotidiano.

\section{CONSIDERAÇÕES FINAIS}

Finalmente, seria importante levantar alguns questionamentos relativos à proposta apresentada.

Parece claro que a Alfabetização Científica e Técnica oferece solução à falta de significado atribuída à educação científica tradicional. Ao partir de projetos vinculados ao cotidiano dos alunos e permitindo que eles próprios delineiem ações no sentido de executá-los, vincula-se saber científico a problemas significativos para os mesmos. Porém, como esperar que eles próprios encaminhem um projeto de solução da problemática construída se muitos dos instrumentos necessários para isso são na verdade objetivos escolares a serem obtidos como resultado da participação no projeto? O próprio Fourez parece encaminhar uma resposta a essa questão, ao indicar que um currículo não deveria ser composto exclusivamente de projetos (Fourez, 1994). Em particular, na etapa "disciplinar do currículo" os conteúdos científicos deveriam ser trabalhados na perspectiva da modelização de fenômenos/situações reais. Mesmo que restrito exclusivamente a uma disciplina, esse procedimento de problematização e de abertura de caixas-pretas seria uma forma de exercitar o potencial explicativo da realidade através do conhecimento científico. Bunge (1974) deixa claro que tal atividade não é só possível como desejável na ciência. Toda explicação/interpretação científica é na verdade a opção pela abertura de caixas-pretas, deixando-se inevitavelmente outras fechadas. Estas últimas acredita-se que sejam em breve também abertas, gerando assim outras ainda fechadas, e assim continuamente. A subseqüente abertura de caixas-pretas conferiria ao cientista e à ciência em geral o sentimento de aproximação sucessiva da realidade.

Nesse caso, deve-se esperar que a realização de projetos seja entendida como uma etapa sintética e aplicada do conhecimento científico trabalhado previamente nos momentos disciplinares do currículo.

Outro ponto que merece consideração se refere ao papel atribuído ao professor na execução do projeto. Como é freqüente o apelo aos especialistas, poderia depreender-se daí que sua função se reduziria à de mero organizador na execução do projeto. Acreditamos, entretanto, que o professor deva ser o primeiro perito a ser consultado. Caberia a ele, com sua bagagem científica, indicar os elementos necessários para a abertura inicial das caixas-pretas, indicando em particular como os conteúdos já estudados em etapas tradicionais do ensino podem ser úteis nesse processo. Também caberia a ele oferecer uma abordagem preliminar aos aspectos não pertencentes a sua formação de referência (por exemplo, aspectos da ciência 
da vida, para professores de física, química e matemática, e vice-versa), assim como indicar bibliografias e centros de pesquisa para acesso a especialistas. As últimas atribuições seriam valiosas, pois ao desempenhar o papel de orientador pluridisciplinar, o professor terminaria por estender sua própria competência para além dos limites de sua formação disciplinar original. Neste sentido, ele seria um elo fundamental entre a etapa disciplinar e a etapa de projeto do currículo.

Finalmente, seria importante não entender a Alfabetização Científica e Técnica como a panacéia para o ensino de ciências. Se a idéia no seu escopo teórico é muito atraente, cabe ainda avaliá-la na sua execução prática, ou seja, em condições reais de sala de aula, com os professores existentes nas redes de ensino, etc. Os resultados apresentados pela equipe de Fourez parecem animadores, porém pouco se sabe de sua viabilidade no cenário nacional.

\section{REFERÊNCIAS BIBLIOGRÁFICAS}

BUNGE, M. (1974). Teoria e realidade. São Paulo: Perspectiva.

CARVALHO, A. M. P., GIL-PEREZ, D. (1993). Formação de professores de ciências. São Paulo: Cortez Editora.

CHEVALLARD, Y. (1985). La transposition didactique: du savoir savant au savoir enseigné. Grenoble: La Pensée Sauvage.

DROUIN, A. M. (1988). Le modéle en questions. Aster, v.7, p.1-20.

DUPIN, J. J., JOHSUA, S. (1993). Introduction à la didactiques des sciences et des mathematiques. Paris: PUF.

FOUREZ, G., MATHY, P., ENGLEBERT-LECOMTE, V. (1993). Un modèle pour un travail interdisciplinaire. Aster, v.17, p.119-140.

FOUREZ, G. (1994). Alfabétisation scientifique et tecnique. Essai sur les finalités de l'enseignement des sciences. Belgique: De Boeck Université.

FREIRE, P. (1970). Pedagogia do oprimido. Rio de Janeiro: Paz e Terra.

KUHN, T. S. (1995). A estrutura das revoluções científicas. São Paulo: Perspectiva.

LARCHER, C. (1996). La physique et la chimie, sciences de modèles. Du mond réel aux connaissances scientifiques, en passant par la modélisation. In: TOUSSAINT, J. (Org.). Didactique appliquée de la physique-chimie. Paris: Éditions Nathan. p.160-178.

PEDUZZI, L. O., PEDUZZI, S. S. (1985). O conceito intuitivo de força e movimento e as duas primeiras leis de Newton. Caderno Catarinense de Ensino de Física, v.2 (1), p.6-15.

PIETROCOLA, M. O. (1999). Construção e realidade: o realismo científico de Mário Bunge e o ensino de ciências através de modelos. Investigações Científicas, Instituto de Física, Universidade Federal do Rio Grande do Sul, Porto Alegre, Brasil, v.4, n.3, dezembro de 1999.

PINHEIRO, T. F. (1996). Aproximação entre a ciência do aluno na sala de aula da $1^{a}$ série do $2^{\circ}$ grau e a ciência dos cientistas: uma discussão. Santa Catarina: Universidade Federal de Santa Catarina. (Dissertação, Mestrado).

ROBILOTTA, M. (1985). Construção e realidade no ensino de Física. São Paulo: IFUSP. (Mimeogr.). 
VILLANI, A, PACCA, J. L. A., HOUSOUME, Y. (1985). Concepção espontânea sobre movimento. Revista de Ensino de Física, v.7 (1), p.37-45.

ZYLBERSZTAJN, A. (1985). As concepções espontâneas em Física: exemplos da dinâmica e implicações para o ensino. Revista de Ensino de Física, v.5 (2), p.3-16.

ZYLBERSZTAJN, A. (1998). Resolução de problemas: uma perspectiva kuhniana. VI Encontro de Pesquisa em Ensino de Física - Ata eletrônica. 


\section{ANEXO}

\section{SÍNTESE DE UMA PROPOSTA DE TRABALHO INTERDISCIPLINAR A ILHA DE RACIONALIDADE EM TORNO DE UM BANHO SAUDÁVEL}

O banho é um hábito cultural $(\mathrm{CP})^{*}$ presente em todos os povos de diversas maneiras (CP). O tipo de banho em cada cultura depende fortemente do clima do local (CP) e também da disponibilidade de água doce (CP).

Basicamente o banho consiste no uso de água doce para limpar o corpo. Pode ser feito diretamente na água de um rio, em uma banheira ou pelo uso de chuveiros e duchas (CP). Em muitos lugares, existe o hábito de tomar banho com água aquecida a uma temperatura (CP) agradável para o ser humano (CP).

A água pode ser aquecida de diversas maneiras (CP), como por exemplo, pelo uso de aquecedores solares (CP), pelo uso de aquecedores a gás $(\mathrm{CP})$ ou, como é mais comum no Brasil, pelo uso de chuveiros elétricos (CP).

Vamos discutir em nosso exemplo o uso de chuveiros elétricos para o aquecimento da água. No interior de um chuveiro há uma resistência elétrica $(C P)$ e através dessa resistência circula uma corrente elétrica (CP) que depende da tensão da casa (CP), de acordo com a lei de Ohm (CP). A resistência se aquece pela passagem da corrente elétrica devido ao efeito Joule $(\mathrm{CP})$.

Quando a água passa pelo interior do chuveiro, há troca de calor (CP) entre a água e a resistência, como resultado a água é aquecida. A temperatura que a água atinge depende tanto da potência do chuveiro utilizado (CP) quanto do tempo que a água fica em contato com a resistência aquecida $(\mathrm{CP})$.

O tempo que a água fica em contato com a resistência aquecida, depende da vazão $(\mathrm{CP})$ da tubulação $(\mathrm{CP})$ que leva a água até o chuveiro. Essa vazão depende também da altura do reservatório de água em relação ao chuveiro $(\mathrm{CP})$.

Normalmente usamos produtos químicos tais como sabonete e xampu para nos banharmos (CP). Esses produtos produzem espuma e ajudam na limpeza de nossa pele e cabelos (CP), mas dependendo do tipo de produto utilizado e da pele da pessoa que se banha, certos produtos podem ser prejudiciais (CP).

O banho também produz sujeira. A água utilizada fica contaminada com produtos químicos. Esses detritos devem ser eliminados da casa através da tubulação que liga a casa até o sistema de esgoto da rua, quando este existe (CP). Geralmente os detritos são lançados nos rios e mares sem nenhum tratamento prévio $(\mathrm{CP})$, podendo acarretar sérias conseqüências $(\mathrm{CP})$ para o meio ambiente $(\mathrm{CP})$. Em poucos lugares $(\mathrm{CP})$ o esgoto doméstico é tratado $(\mathrm{CP})$ antes de ser eliminado. Um banho demorado contribui, ainda, para o agravamento de outros problemas ambientais como a escassez de água (CP) e a degradação ambiental causada pela construção de novas hidrelétricas, devido a maior demanda de energia elétrica (CP).

O mercado de produtos utilizados no banho e cosméticos em geral (CP) move verdadeiras fortunas em dinheiro anualmente $(\mathrm{CP})$. As indústrias químicas $(\mathrm{CP})$ se utilizam da

\footnotetext{
* CP significa caixas-pretas que podem ser abertas ou não, de acordo com a discussão feita anteriormente.
} 
publicidade (CP) para aumentar suas vendas (CP). As propagandas (CP) de xampus e sabonetes exploram a imagem (CP) de uma bela mulher branca (CP) ou de um homem branco banhando-se para incentivar (CP) as outras mulheres e os outros homens a comprarem seus produtos.

Toda essa discussão em torno de um simples banho nos mostra como uma questão cotidiana pode ser trabalhada com um enfoque interdisciplinar, conforme discutimos no corpo principal do texto. 